\title{
The influence of project-based learning approach in the english oral production
}

\section{The influence of project-based learning approach in the english oral production}

Noemi Mercedes Remache Carrillo. ${ }^{1}$, Gabriela Alejandra Robayo Dávalos. ${ }^{2}$, Viviana Vanessa Yanez Valle. ${ }^{3}$

\begin{abstract}
.
The objective of this study was to determine the effect of the application of project-based learning on the development of oral production (speaking) of the English language in fiftytwo students who attend to Unidad Educativa Pelileo in the elementary level A.1.2 according to the Board of Ecuadorian education. The qualitative-quantitative method was used in the research; qualitative because the performance of students in class and quantitative was observed because the grades obtained in the pre and post-test were statistically analyzed. The population for this research was divided into two groups: control with twenty-seven students and the experimental group with twenty-five students. Furthermore, the research was quasiexperimental, bibliographic and field, since the experimental group was observed and submitted to an intervention plan with a project-based learning treatment. The instrument used to evaluate the independent variable was the Key English Test (KET) (MOCK) test that was applied before and after the intervention plan. The data obtained were tabulated, analyzed, interpreted and subjected to a T-student test in order to verify the hypothesis and conclude that the null hypothesis was rejected and the alternative hypothesis was accepted. It means that the treatment with project-based learning contributed to a significant improvement in oral production performance, reflected in the parameter scores of: grammar

1 Escuela Superior Politécnica de Chimborazo, Centro de Idiomas, Riobamba, Ecuador, noemi.carrillo@espoch.edu.ec

2 Unidad Educativa Pelileo, Pelileo, Tungurahua, Ecuador, gabita2085@ hotmail.com

3 Escuela Superior Politécnica de Chimborazo, Centro de Idiomas, Riobamba, Ecuador, viviana.yanez@espoch.edu.ec
\end{abstract}


and vocabulary, pronunciation, and interactive communication established in the assessment instrument. Therefore, teachers are suggested to apply project-based learning in the development of oral production.

Keywords: Learning Projects, approach, oral production, performance

\section{Introduction.}

According to the English Proficiency Index (EPI) 2017 Ecuador has a low English proficiency level. It has been ranked in the 55th place after Guatemala. Even though Ecuador stands out for an above-average gained since 2007 until 2017, it is still one of the countries with the lowest English proficiency levels in Latin America. The deficient oral production level could be due to the lack of interaction among Ecuadorian students and native English speakers. Although Ecuador has been mentioned as a tourist country it is not possible to keep a conversation with native speakers easily. Foreign people can be found just in certain places such as Baños de Agua Santa, Shell, Tena, Quilotoa and other specific cities. However, they seem to be reluctant to make friends. For that reason, it is not possible to address them for achieving oral interaction.

The students were assessed the speaking skill and the results showed a deficient of the English production level on the pre-test. For that reason, it is important to be aware of the importance that oral production has. Oral production is an essential productive skill which has to be developed taking many considerations such as what we say, to whom we are talking to, and how we want to convey the message. It is also important to take into account the already mentioned points because language has to be used appropriately in order to communicate with other people effectively.

Furthermore, Project-Based Learning activities could be used to enhance oral production. Teachers could use this teaching method to have students interacting together on assigned tasks. That will allow that they can speak between them and communicate in a student centered class. Besides, according to Leaver \& Stryker (1989) "students who work on projects show increased motivation and engagement in their studies". For that reason, project-based learning activities were implemented on this study to help learners improve their speaking skill.

The implementation of projects in class could be a good option to have the students practice the speaking skill in the target language. It will allow interaction, communication and participation in a student centered class where they will be the ones who practically manage the class. Projects will also be a good option to practice oral production because they will have to present the work product of their projects. This for sure will make them practice the 
oral skill more than what they were accustomed, having hopefully an improvement on this skill.

Another factor that may cause low oral production development is the use of traditional methodology. According to Andrew (2012) with traditional methodology, students have limited opportunities to intervene orally through projects in a teacher-centered class. This also may affect students' confidence which may lead students to fear of speaking in English; if students do not want to speak in the target language, they will not be confident enough to interact among them, thus they may not want to continue learning English.

In addition, teaching speaking requires activities which go along with the students' needs. The use of inappropriate activities to teach this productive skill demotivates students to practice conversations among them. It is necessary to use innovative activities in order to get the students' attention (Barker \& Westrup, 2000). However, it seems that many if not most EFL teachers are accustomed to teaching-centered classes where they are the ones who explain what the subject matter is about while the students keep just sitting and listening to the teacher's instructions; hence, they have little or no spoken interaction. This, for sure causes non-effective spoken communication among students, limiting even more their oral production in the target language.

This research is relevant because there is not any other research related to this theme developed at Unidad Educativa Pelileo. For this reason, this work is innovative because it was focused on developing oral skills through the use Project-based learning approach. As the projects are closely related to solving everyday problems, the students could find a useful tool to interact orally in real situations.

This research is important because it permits to understand the influence of Project-Based Learning activities in the low English Oral Production level applied to 25 ninth graders at Unidad Educativa Pelileo, located in Pelileo-Tungurahua, in the September 2017- June 2018 school year. English oral production is vital to communicate with others, thus it is necessary to put special emphasis on teaching this skill because English is considered lingua franca and there are thousands of people who speak it all over the world. Besides, Ecuador is frequently visited by tourists from many parts of the world who communicate through English. Thus, it is important to achieve a good proficiency level on this skill.

Since speaking is the main way to communicate orally, this work is of local and national interest because the main goal is to help improve the oral production (speaking) on the students. Besides, the implementation of Project-based learning approach allowed the students to face real life situations and they could practice the target language by using appropriate vocabulary and grammatical structures in context. Also, it can be added that most teachers are concerned about the importance of oral production on the students. Thus, it is 
always helpful to devote all efforts to find appropriate techniques and strategies to improve oral production.

It is necessary to mention that this research was feasible because it was not difficult to implement Project Based Learning Activities with the students at Unidad Educativa Pelileo. Besides, it was not necessary to spend money because the projects were very simple to develop. Additionally, the human resource was provided by the students and the teacher who shared information to develop the projects. For all those reasons, this research was feasible to achieve, and it could be implemented not only with elementary students, but also with all levels as necessary.

This research has appositive impact, because it was possible to observe an increment in the post test's scores in relation to the pre test's grades. Besides, not only the scores increased, but also shows an improvement in the pronunciation, grammar and interactive communication. These factors may help the students feel more comfortable when they interact in class and outside of it, or when they have to use the target language to communicate in real situations.

Finally, it is also important to highlight that the beneficiaries are absolutely the students at Unidad Educativa Pelileo, because they belong to tourist places such as Pelileo where foreign visitors go frequently, therefore they can be able to communicate through English with foreign people. Besides, teachers and the institution are beneficiaries too because Projectbased activities could be implemented at this high school to help its students improve the oral production.

\section{Project-Based learning Approach}

Regarding Project-Based learning, Capraro, Whitfield, Etchells, and Capraro (2016) argue that projects permit the students to show their capacity to work in pairs or groups in an effective manner. At the same time, they can be able to manifest their critical thinking as well as their potential to solve the problems that could be found in the project working process. Besides, group work is seen as one of the most vital features in any project development because projects can help the students enhance teamwork and communication skills. Thus, it is vital to have successful cooperation and collaboration among the people involved in the project because failure can be experienced in the entire work when these features are not accomplished.

Furthermore, according to Laur (2013), projects are sometimes simulated practices in the classroom that are graded by the teacher and then returned to the student with some feedback so that they can improve their work. It is stated that projects are most of the time almost real activities created and completed for the students. These approach demands them not only to put in practice their critical thinking, but also dare them to go from basic memorization of 
content to active involment and participation. Working with projects may encourage the studetns to be involved in their own learning. Thus, teachers should help learners in order to choose an appropriate project which can certainly help them improve the needed skills.

Additionally, it has been stated that Project-Based Learning approach could be used by teachers as an action to make the students the main characters in the classroom. Besides, working with projects could help teachers work in a dynamic and interacting class because, according to Blank (as cited in Aytekin, 2011:2) "in project-based learning, students plan, implement, and evaluate projects that have real-world applications beyond the classroom". Thus, real world activities could motivate students to actively participate in class while their performance is constantly monitored by the teacher.

Teachers also need to recognize whether the students are getting knowledge or not. Besides, educators should have a strategy in order to deal with the students' needs and interests. When teachers get to know his or her students, they will be able to guide them throughout the project process by providing enough support to them. Therefore, educators should not work in isolation, they should be encouraged to work and get along with their colleagues so that lesson plans, assessment rubrics, and activities can be shared and feedback can be provided and received. Thus, a peer-supported learning environment can be built in order to benefit the students in the teaching-learning process (Laur, 2013).

Another reason to state that Project-Based Learning approach could help in the teaching learning process is because projects can be used in primary or secondary education whenever necessary. Besides, a student-centered environment is promoted when projects are used in class. In addition, students work on their own or in groups to obtain and present the information about the selected topic. Something that has to be highlighted about working with projects is that they can be daily life issues which can be solved with a solution through promoting students' high-order thinking skills (Tan and Chapman, 2016).

Project-Based learning activities are used in subject matters like Mathematics, English, Visual Media Analysis and Production, Physics, and Art. In Math, students are able to use tools to determine measurements to find perimeter and area of geometric figures as well as to calculate areas of polygons and to apply mathematical processes. In English language learning, students are expected to work in cooperation with others to produce writing and oral outcomes and establish communication. Besides, in Visual Media Analysis and production students produce visual and media text for creating communication. In Physics, learners answer laboratory and field research questions. Finally, in Arts, students communicate their ideas through art work by challenging imagination (Capraro et al., 2016:10-11). 
The development of projects consists mostly of a student-centered environment where learners are the main participants. Nevertheless, teachers also play an important role during the working process. They are in charge of monitoring constantly throughout the whole development in order to provide feedback if necessary. Teachers have to be conscious that learners will make as many mistakes as they can. However, this is not a good reason to stop their work, because as mentioned before, project-based learning activities are carried out in a learning environment where mistakes are allowed and seen as part of the learning process (Straub et al., 2017).

It is important to mention that the aim of introducing project work in the classroom is basically to let the students learn in an autonomous way. They can also experience activities that can be faced in real life situations during the project development. All these activities permit the students gain important skills such as cooperation, collaboration, communication and independent learning. Thus, they may become more aware of their own learning and may be prepared for future challenges not only in the educational field, but also in the general situations that could be faced during their life (Tan and Chapman, 2016).

\section{Oral production}

Regarding to this topic; oral production is represented by the spoken form of communication. In this sense, Bailey (2003) claims that speaking can be considered to be essential because it is a necessary ability not only to maintain a real time conversation, but also to achieve language development. When people have oral interaction, immediate response among the participants is usually required. Besides, in this interaction, the speaker expresses thoughts and messages whilst the listener is ready to reply as soon as the speaker stops talking. For that reason, it is stated that in many if not all foreign language courses; the speaking skill is the most required to be learned.

In today's world, speaking English has become not only a matter of knowledge, but also a necessity; new generations require people who speak English. It could happen because English language can be considered as a status symbol that is used and understood worldwide. Besides, English is important because all multinational companies hire people who are able to speak this language with a good level of fluency and correctness. It is also stated that the number of English speakers has increased all over the world. Thus, living without English language could not be afforded nowadays (Robert, 2010).

According to Halliday (1989), the chief means of communication is speaking; it is apparently easily acquired as an innate characteristic of human beings. Besides, it has been stated that speaking can be seen as a set of meanings that are encompassed by a set of expressions. Other skills such as reading and writing are learned in an educational setting when people enroll to educative institutions, whilst speaking is an ability people were born with. Additionally, speaking is important in order to check whether students have understood certain class topics 
or not, because it is easier and more efficient to ask in oral way rather than conducting a set of written questions every time.

The speaking skill is influenced by a series of circumstances i.e., real time performance situations, instantaneous presence of participants, immediate interaction, the same setting, and the desire of transmitting the speaker's point of view. These features are somehow or other shared in low or high degree and are used by the speaker though different kinds of registers (formal or informal) (Biber, 2006). The speaking skill has a very close relation with listening because speaking can be regarded as unworthy when there is not an interlocutor to reply or at least listen to somebody else's words.

Moreover, an excellent opportunity for learners to become aware of what speaking involves is provided when focusing on formal language. In addition, when speaking is used effectively, it could lead to the development of useful planning and delivery strategies. Although formal speaking is affected by the performance conditions of planning, time pressure, support, and standard of performance, students should be ready to deal with all those aspects, because it helps learners express their ideas in a standardize way so that the message can be conveyed in formal setting and context (Nation \& Newton, 2010).

Apart from that, according to Robert (2010), informal language is mostly used in speaking and it is placed out of conventional or standard language. One example of informal language is the use of contractions. They are used in everyday spoken language and informal writing. Slangs are other example of informal language. These expressions that are not considered within formal context consist both of coined words and phrases, and of new or extended meanings attached to existing terms. Slangs commonly either pass into disuse or come to have a more formal status and are used attempting to find fresh and vigorous, colorful, pungent or humorous expression. Besides, these kinds of words try to make the language friendlier and are used to simplify the meaning of words in a better manner.

Additionally, another example of informal speaking is when people use phrasal verbs. Those words are an important part of English language especially in spoken and are members of a large group of verbs called 'multi-word verbs' (Robert, 2010). Colloquial words are also included in informal speaking use. These kinds of words are used especially in casual conversation. Another feature of informal spoken language is reduced speech. It refers to the tendency of joining two words and transform them into just one utterance i.e., the words "going to" may sound like "gonna". They are actually systematic, rule-governed variants that are natural in spoken English not just "sloppy speech" resulting from the speaker's laziness or carelessness (Bailey, 2003).

Two alternatives can be suggested. First, learn pronunciation from the beginning and speak from the beginning. Second, learn without pronunciation, but do not speak (you will start 
speaking at a later stage, after learning pronunciation). If a perfect pronunciation is not accomplished at the beginning of the course, students should not be worried; their pronunciation should fit between the following parameters: 1 right sounds have to be usedthe speaking version of foreign language learners may get along with English sounds. 2 the right syllable has to be always stressed (Robert, 2010).

Equally important to mention, learners have to be trained in order to develop the speaking skill, because they will not become proficient speakers just by listening and understanding the target language. It is supposed that speaking should naturally be led by listening, especially at the phonological level. For that reason, it is vital to learn to recognize sound patterns as well as phonological aspects of English language because there is a clear connection among listening and speaking. For that to be done, some techniques for oral production should be taken into account i.e., controlled, guided, and free oral work Brumfit et al., (1986).

First, controlled oral work is considered as a flexible technique for language interaction in the spoken form. It is suitable for oral presentation and practice of phonological, lexical and grammatical items. This kind of work can be used as controlled or guided oral production with the aim to fulfill communicative criterion. It is also possible to use controlled oral work from the very starting lesson even with elementary level students because simple introductions could be employed at this stage. Besides, drills could be used; they could be very structured so that the possibility to make mistakes could be reduced when practicing them because the students may have to answer tightly questions without open answers. That could help learners to achieve fluency as well as confidence at a certain point Brumfit et al., (1986).

Second, guided oral work is another form to practice spoken English. The objective of this activity is to assign the students a limited time to practice what they have learned in class. The oral practice is allowed; however, some restrictions are provided when achieving guided work. Some guided oral work can also be given through the use of appropriate questions and answers. At the same time, some freedom is allowed them in order to use their own ideas into the exercises developed in class. Guided work can also be used in a structured way to check the students' exercises from controlled guidance to more flexible work Brumfit et al., (1986).

Third, free oral production provides the students the opportunity to produce in a natural way the language that has been learned. Besides, they can put in practice all their knowledge in several more or less controlled situations. This process can be developed at all the levels of teaching. However, it is especially important in the more advanced levels because at that stage is where the students have the instruments needed i.e., knowledge about grammar 
patterns, lexicon, language usage, etc., to express their messages and thoughts Brumfit et al., (1986).

Not only the activities above mentioned should be developed help the speaking skill, but also other aspects should be considered because spoken language has difficult parts to be achieved such as fluency and accuracy. A good speaker should be both fluent and accurate specially students at advanced levels. On the one hand, fluency is the ability to use spoken language in a fluid and confident way in a consistent percentage with the standard of the pertinent native speaking community (Bailey, 2003).

\section{Methodology}

This study was supported by bibliographical, documentary and transversal investigation. Besides, field research has been applied considering that this research permitted to study an experimental group in the classroom. It permitted to obtain real information in order to reach the study's objectives. Additionally, bibliographical research has been developed during all the study process so that concepts and thoughts of other authors can be analyzed and explored because they have made a good contribution to this study.

Moreover, qualitative and quantitative method of research was employed; this research allowed organizing, analyzing and interpreting the data collected from the test applied before and after the implementation of project-based learning approach with the experimental group. The analysis of the data helped to verify and accept the null hypothesis, as well as to draw conclusions and recommendations about the implementation of Project-Based Learning Activities for the oral production development.

The descriptive and applied type of research has been chosen for this research. Besides, these types of research aim at reporting the results found after the data analysis of the results. Besides, it attempted to find a solution to the oral production problems found through the implementation of Project-Based Learning Activities with the students.

Moreover, it is a quasi-experimental design because it attempted to determine the differences among the control and experimental group after the implementation of project-based learning approach. Both groups took a pretest and a post-test in order to measure the results of this study. Two variables were manipulated by the same teachers; the independent variable, which is project-based learning approach and the dependent variable that is oral production (the speaking skill) development.

This research was developed at Unidad Educativa Pelileo that is located in Tungurahua province. A total of 52 students was the population; the control group was comprised of 27 students, whilst the control group had a total of 25 learners from the already mentioned high 
school. It is important to mention that working on this sample or experimental group helped understand how project-based learning affected English oral production on the students.

Chart 1. Population and sample

\begin{tabular}{lcc}
\hline \multicolumn{1}{c}{ Population } & Frequency & $\%$ \\
\hline Experimental group & 25 & 48 \\
Control group & 27 & 52 \\
Total & 52 & 100 \\
\hline
\end{tabular}

Source: Direct investigation

Created by: Robayo, G. (2017)

The elements which were employed for the data collection: a pre-test and a post-test as well as observations. Besides, a notebook was used to write down the most important details during the observations. Pre and Post-tests were carried out with the students at Unidad Educativa Pelileo.

First of all, the population was divided into two groups, the control group with 28 students and the experimental group with 25 learners. Second, the instrument used was the speaking section of a Key English Test examination, it was comprised of three parameters that were awarded five points each i.e., grammar and vocabulary, pronunciation, and interactive communication. Besides, the speaking section consisted of two parts; in the first part, the students had to answer some questions about basic personal information in 4 to 5 minutes; second, the students were given some cards that contained information and prompts on it, then they were required to interact among them providing and requesting information related to the clues on the cards in 3 to 4 minutes.

Using the instrument previously mentioned in this section, a pre-test was conducted to the students. After the analysis of the pre-test results, the researcher has developed a class intervention for improving students' oral production through Project-Based learning activities during 6 weeks in October and November 2017. This intervention was applied for 18 academic hours. Finally, a post-test was conducted to the control and experimental group.

First of all, the students were divided into control and experimental group. Then, a pre-test was conducted to both groups. The test was the speaking part of a mock KET examination, it was comprised of three parameters i.e., grammar and vocabulary, pronunciation, and interactive communication. After that, the treatment with project-based learning activities with the experimental group was executed. Then, a post-test was conducted to the control and experimental group. More statistics information was collected in charts and figures that are detailed as follows. 
The comparison of averages obtained in the three parameters of test of the pre-test and the post-test. Figure two shows the students' individual scores from the control and experimental group obtained in the Pre-test and post-test. Comparison of scores according to each parameter obtained by both groups in the pre-test and post-test. The comparison of scores according to each parameter (grammar and vocabulary, pronunciation and interactive communication) obtained by the experimental group in the pre-test and post-test. The frequencies of the total scores obtained in the pre-test and post-test by both groups.

All the data was tabulated, analyzed, and interpreted by using Excel software. The information permitted to test the hypothesis so as to draw conclusions about the influence of project-based learning approach in the English speaking skill development.

\section{Results}

For this research, the students were divided into two groups, the control group with 28 students and the experimental group with 25 students. Both groups attended to classes with the difference that the students from the experimental group were subjected to a treatment with Project-Based Learning. Besides, the speaking part of a Key English Test (KET was conducted to the students. It consisted of three parameters i.e., grammar and vocabulary, pronunciation and interactive communication. Each parameter was graded out of 5 points, having 15 points in total. Once the pre and post-tests' grades were obtained, the analysis of results was developed. The projects developed by the students were specifically selected according to the students' level.

It is important to mention that the analysis of the results showed that the treatment developed with the experimental group showed positive results. The treatment was effective because better grades were obtained by the students from the experimental group in comparison with the students form the control group. The scores from the experimental group were higher in the three parameters mentioned before. The results of the pre-test and post-test conducted to the students from the control and experimental group were displayed, analyzed and interpreted.

Finally, the findings of the study are shown after having processed the data. Standard deviation was applied by analyzing statistically the correlation of the variables. Besides, a Ttest was considered in order to verify the hypothesis. This process allowed presenting the results of the study in the following charts, graphs, and figures.

Chart 2 Averages from the control and experimental group in the pre and post-test.

\begin{tabular}{lccc}
\hline \multicolumn{1}{c}{ TEST/GRUPO } & $\begin{array}{c}\text { Grammar and } \\
\text { Vocabulary }\end{array}$ & Pronunciation & $\begin{array}{c}\text { Interactive } \\
\text { Communication }\end{array}$ \\
\hline Pre-test control group & 2,500 & 2,000 & 2,500 \\
Post-test control group & 3,653 & 3,538 & 3,500
\end{tabular}




\begin{tabular}{llll} 
Pre-test experimental group & 2,200 & 2,000 & 2,560 \\
Post-test experimental group & 4,440 & 3,960 & 4,120 \\
\hline
\end{tabular}

Source: Direct Research

Created by: Robayo, G. (2017)

Graph three shows the averages form the control and experimental group in the pre and posttest. The control group obtained an average of 2.500 in grammar and vocabulary, 2.00 in pronunciation, and 2.500 in interactive communication in the pre-test. The same group in the post-test had 3.653 in grammar and vocabulary, 3.518 in pronunciation, and 3.518 in interactive communication. Thus, the averages in the post-test from the control group have increased.

Similarly, graph three also shows the averages form the experimental group. This group has achieved 2.200 in grammar and vocabulary, 2.00 in pronunciation and 2.560 in interactive communication. Whilst, in the post-test, the averages were: 4.440 in grammar and vocabulary, 3.960 in pronunciation and 4.120 in interactive communication. These results indicate both, higher scores in the post-test compared with the pre-test scores, and higher scores in the experimental group's scores in the post-test compared with the control group's post-test' results.

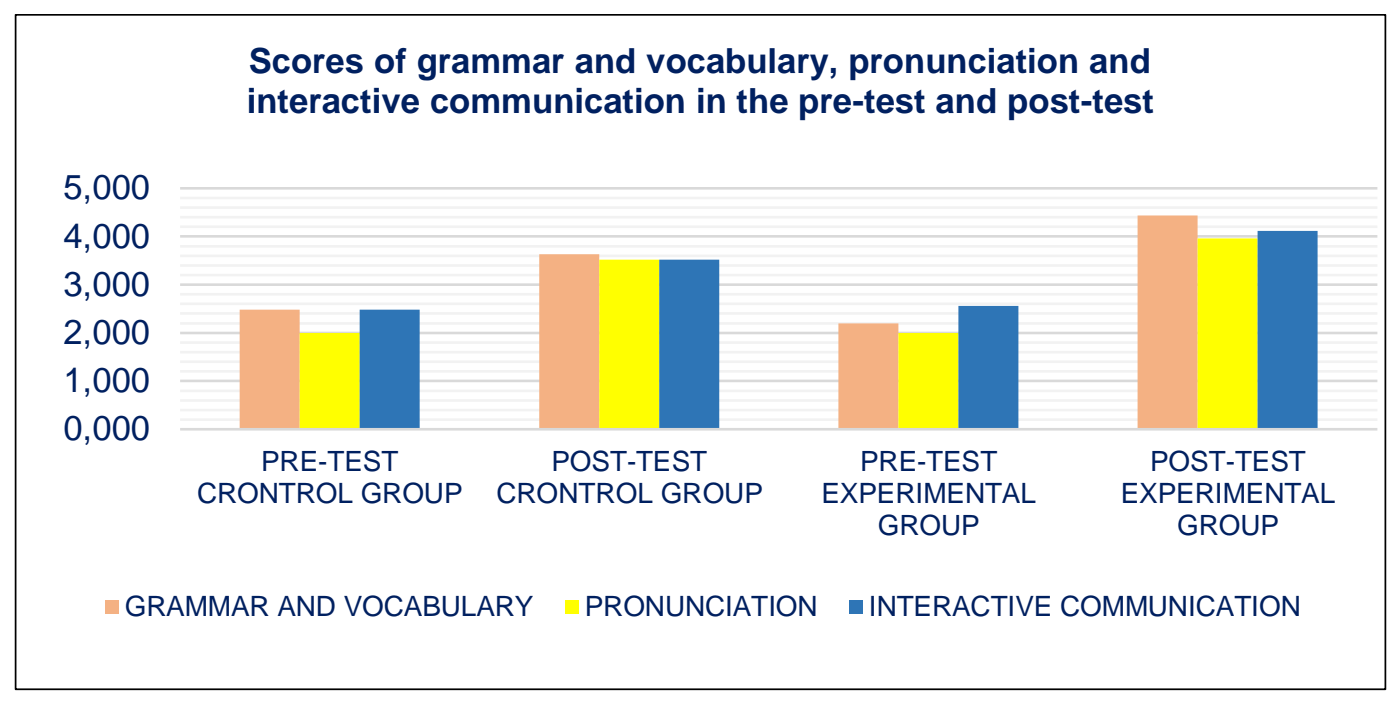

Figure 1. Comparison of averages obtained in the parameters of grammar and vocabulary, pronunciation and interactive communication in the pre-test and the post-test.

Source: Direct Research

Created by: Robayo, G. (2017)

Furthermore, figure 1 helps to show that both the control and experimental group have almost similar percentages of scores in the pre-test. However, there are some differences in the posttest's results in both groups. The scores from the experimental group are higher in comparison with the grades from the control group. The scores have increased in the three 
parameters. These first results; begin to provide and idea that the treatment applied to the experimental group were helpful.

Furthermore, the pre-test results from the control and experimental group show that the average scores do not reach 3 points in any parameter. Nonetheless, the post-test results in all the parameters of the control group are higher than 3 points out of five. Nevertheless, the post-test's scores from the experimental group are higher than 3 points in pronunciation and reach the highest scores in grammar and vocabulary and interactive communication, these parameters have reached 4 out of 5 points; this represents a better performance from the experimental group than the control group. Thus, there is and increment in the scores in the post-test from the experimental group after the treatment with project-based learning approach.

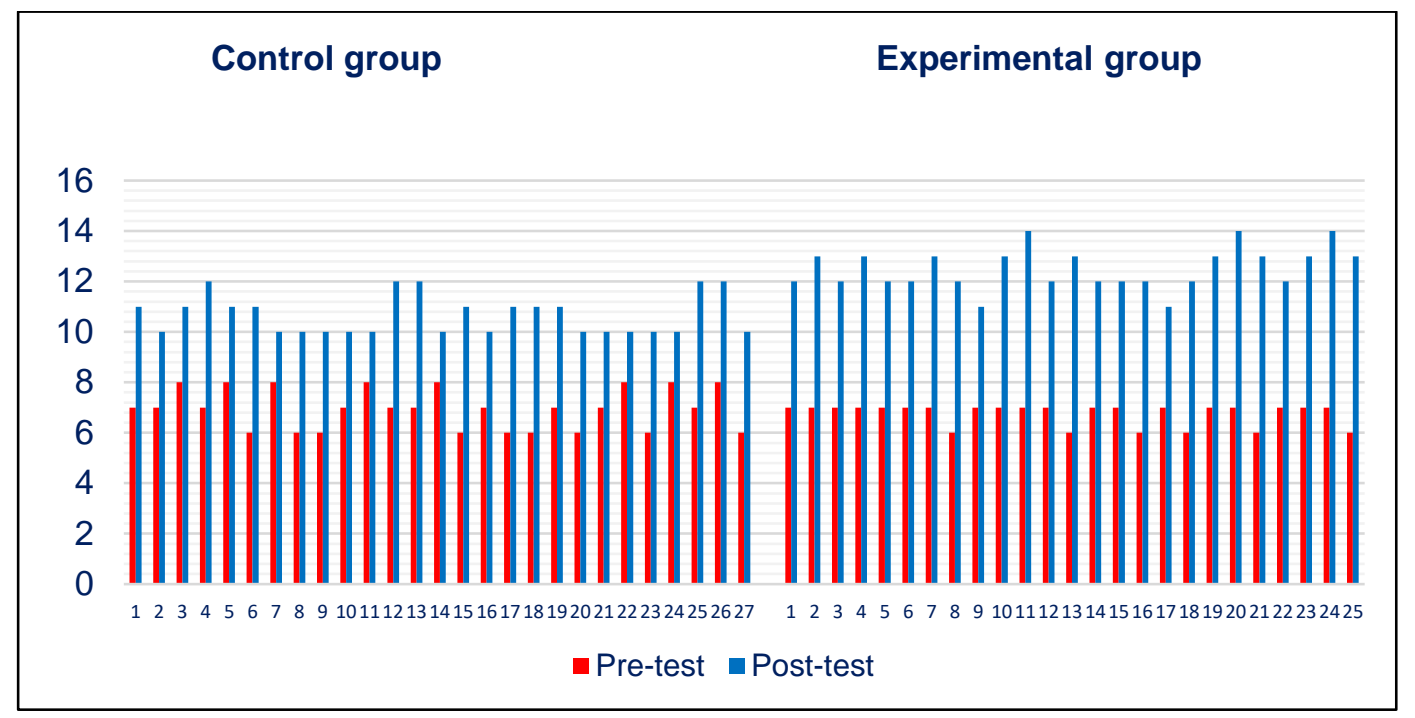

Figure 2. Students' individual scores from the control and experimental group obtained in the Pre-test and Post-test.

Source: Direct Research

Created by: Robayo, G. (2017)

Figure 2 shows the grades obtained by the students individually in the three parameters grammar and vocabulary, pronunciation, and interactive communication. The students from the control group obtained lower grades than the ones from the experimental group. The lowest grade obtained in the pre-test by the students form the control group was 6 points, while the highest score was 14 points.

Furthermore, the lowest scores obtained by the students from the experimental group in the pre-test were similar to the ones obtained by the students from the control group (6 points). On the other hand, the highest score obtained in the post-test by the students from the experimental group was 14 out of 15 points. Thus, it possible to observe that the students from the experimental group obtained betters results individually talking, in comparison with 
the control group's individual scores. Besides, the post-test's grades from the experimental group are also higher in comparison with the post-test's grades from the control group.

Chart 3. Mean, variance and standard deviation from the control and experimental group's scores in the pre-test and post-test: grammar and vocabulary, pronunciation and interactive communication.

\begin{tabular}{lcccc}
\hline \multirow{2}{*}{ Parameters } & \multicolumn{4}{c}{ Scores } \\
\cline { 2 - 5 } & \multicolumn{2}{c}{ CONTROL GROUP } & \multicolumn{2}{c}{ EXPERIMENTAL GROUP } \\
& Pre-test & Post-test & Pre-test & Post-test \\
\hline Mean & 6,96 & 10,67 & 6,76 & 12,52 \\
Variance & 0,65 & 0,62 & 0,19 & 0,68 \\
Standard deviation & 0,81 & 0,78 & 0,44 & 0,82 \\
\hline
\end{tabular}

Source: Direct Research

Created by: Robayo, G. (2017)

In chart 3, the results from the mean, variance, and standard deviation corresponding to the control and experimental group in the pre and post-test are showed so that they can be compared. The following data corresponds to the control group's pre-test' results: mean 6.96, the variance was 0.65 and the standard deviation was 0.81 . In the post-test, from the same group, the results were: mean 10.67 , variance 0.62 , and standard deviation 0.78 . These results show a small increment in the post -test compared with the pre-test. Moreover, the experimental group obtained the following results in the pre-test: mean 6.76, variance 0.19 , and standard deviation 0.44 . Whilst in the post-test the results were: mean of 12.52, variance 0.68, and Standard Deviation 0.82. By comparing these results, it can be seen that the experimental group achieved a significant increment in the post-test's scores. Thus, the results obtained in the Post-test by the experimental group may be seen as an improvement that could be awarded to the implementation of activities related to project-based learning.

Figure 3. Comparison of scores according to each parameter (grammar and vocabulary, pronunciation and interactive communication) obtained by the control group in the pre-test and post-test.

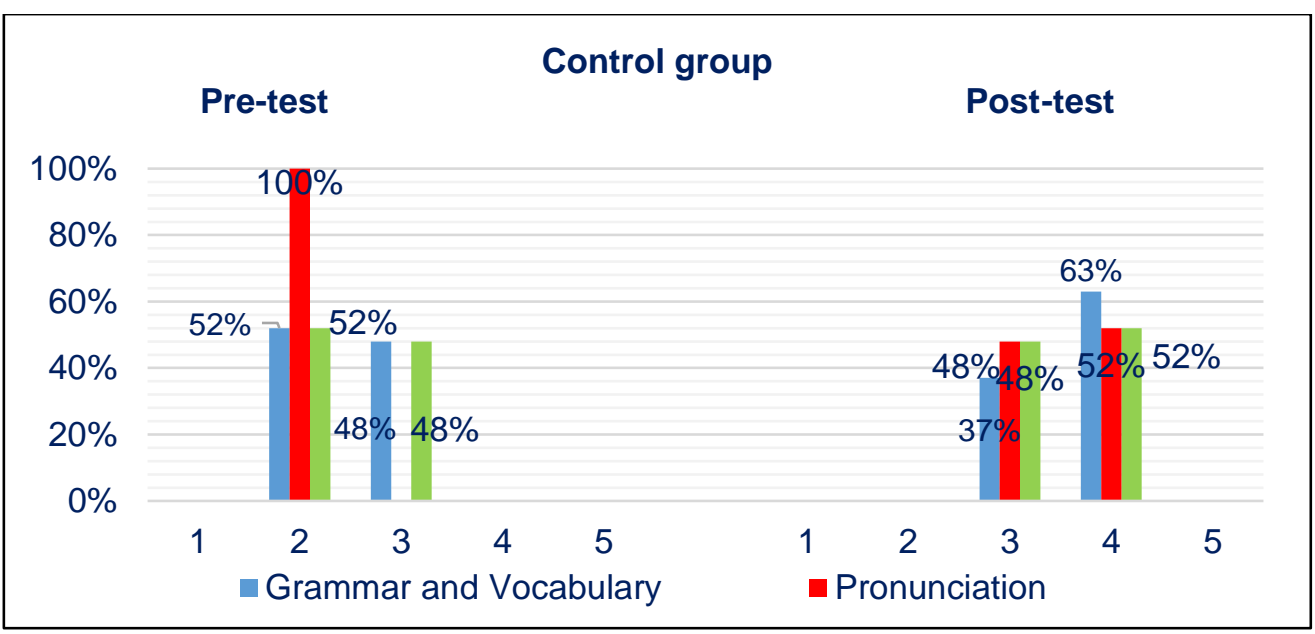


Source: Direct Research

Created by: Robayo, G. (2017)

In Figure 3, it is possible to observe the results from the pre-test from the control group, they are showed as follows: $52 \%$ of the students obtained 2 points and $48 \%$ of them got 3 points in the parameter of grammar and vocabulary. In addition, $100 \%$ of the students reached 2 points in the parameter of pronunciation. Besides, a $52 \%$ obtained 2 points and $48 \%$ had 3 points in the parameter of Interactive Communication.

On the other hand, in the parameter of grammar and vocabulary, the students' percentages were: $37 \%$ with 3 points and $63 \%$ with 4 points. Besides, the students obtained $48 \%$ with 3 points and $52 \%$ got 4 points in the parameter of pronunciation. Additionally, $48 \%$ obtained 3 points and $52 \%$ obtained 4 points in the parameter of Interactive Communication. Thus, it can be observed that the students form the Control Group had a small increment in the scores in the post-test compared with the pre-test' results.

Figure 4. Comparison of scores according to each category (grammar and vocabulary, pronunciation and interactive communication) obtained by the Experimental group in the pretest and post-test.

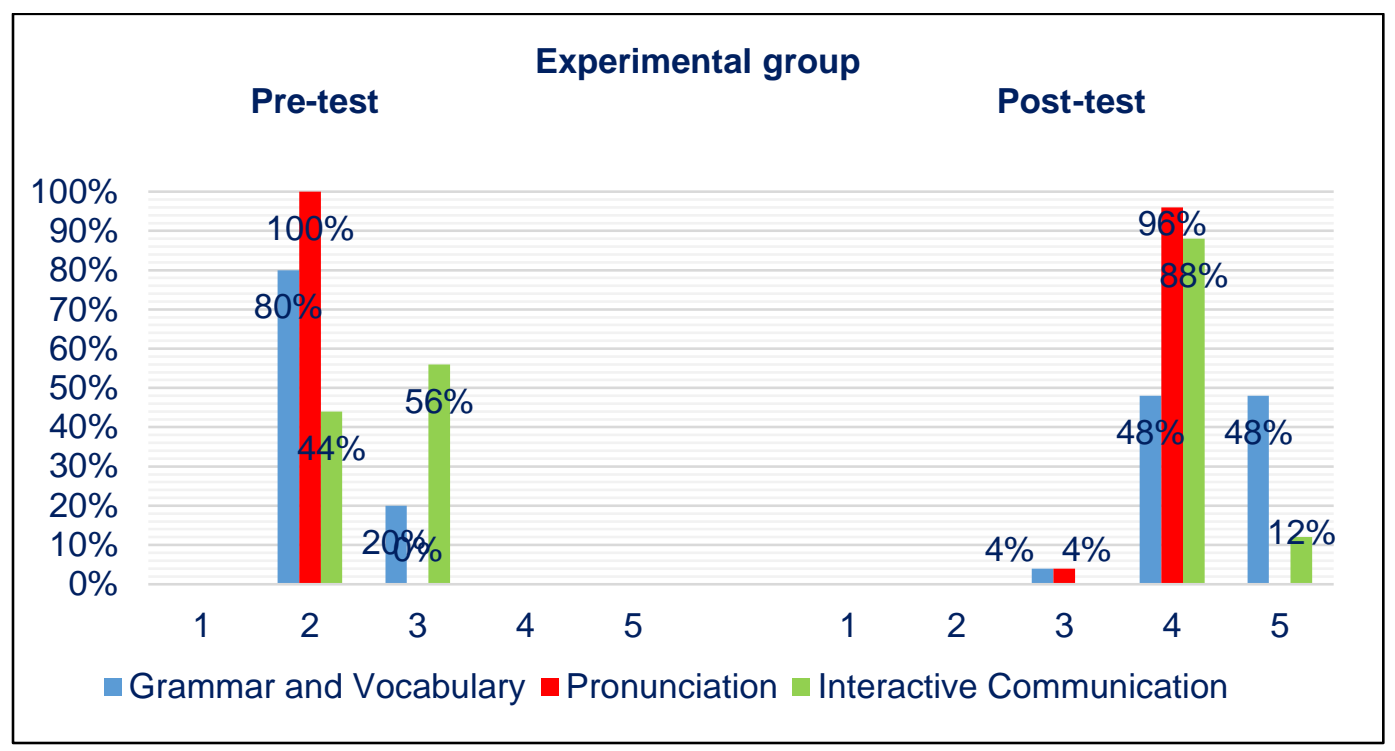

Source: Direct Research

Created by: Robayo, G. (2017)

Figure 4 shows the pre and post-test's results from the experimental group. In the pre-test, it can be seen that $80 \%$ of the students got scores of 2 points and $20 \%$ obtained 3 points, these results belong to the parameter of grammar and vocabulary. Additionally, $100 \%$ of the learners obtained 2 points in pronunciation. Besides, $44 \%$ of the students obtained 2 points and $56 \%$ got 3 points in the parameter of interactive communication. 
Apart from that, the experimental group has achieved the following percentages in the posttest. $4 \%$ of the students got scores of 3 points, $48 \%$ obtained 4 points, and $48 \%$ got 5 points in the parameter of grammar and vocabulary. Besides, $4 \%$ of the learners obtained 3 points, and $95 \%$ got 4 points in pronunciation. In addition, $88 \%$ of the students obtained 4 points and $12 \%$ got 5 points in the parameter of interactive communication. Thus, it could indicate that the use of project-based learning approach influenced positively and helped the students get higher grades in the post test. Finally, Pronunciation and Interactive communication were the parameters that had achieved the highest increase among all the categories.

Chart 4. Frequencies from the total scores obtained in the Pre-test and Post-test by the Control and Experimental group.

\begin{tabular}{lcccccccc}
\hline \multirow{2}{*}{ LINKERT SCALE } & \multicolumn{3}{c}{ CONTROL GROUP } & \multicolumn{3}{c}{ EXPERIMENTAL GROUP } \\
& \multicolumn{2}{c}{ Pre-test } & \multicolumn{2}{c}{ Post-test } & \multicolumn{2}{c}{ Pre-test } & \multicolumn{2}{c}{ Post-test } \\
\cline { 2 - 11 } & FQ & $\%$ & FQ & $\%$ & FQ & $\%$ & FQ & $\%$ \\
\hline Excellent (A) & 0 & 0 & 0 & 0 & 0 & 0 & 3 & 12 \\
Good (B) & 0 & 0 & 13 & 48 & 0 & 0 & 22 & 88 \\
Satisfactory (C) & 0 & 0 & 14 & 52 & 0 & 0 & 0 & 0 \\
Needs Improvement (D) & 18 & 67 & 0 & 0 & 19 & 76 & 0 & 0 \\
Unsatisfactory (E) & 9 & 33 & 0 & 0 & 6 & 24 & 0 & 0 \\
& $\mathbf{2 7}$ & $\mathbf{1 0 0}$ & $\mathbf{2 7}$ & $\mathbf{1 0 0}$ & $\mathbf{2 5}$ & $\mathbf{1 0 0}$ & $\mathbf{2 5}$ & $\mathbf{1 0 0}$ \\
\hline
\end{tabular}

Source: Direct Research

Created by: Robayo, G. (2017)
A: Excellent 15-14 Points,
B: Good 13-11 Points
C: Satisfactory 10-9 Points
D: Need Improvement 8-7 Points

E: Unsatisfactory 6-0 Points.

FQ: Frequency

$\%$ : Percentage of Frequency.

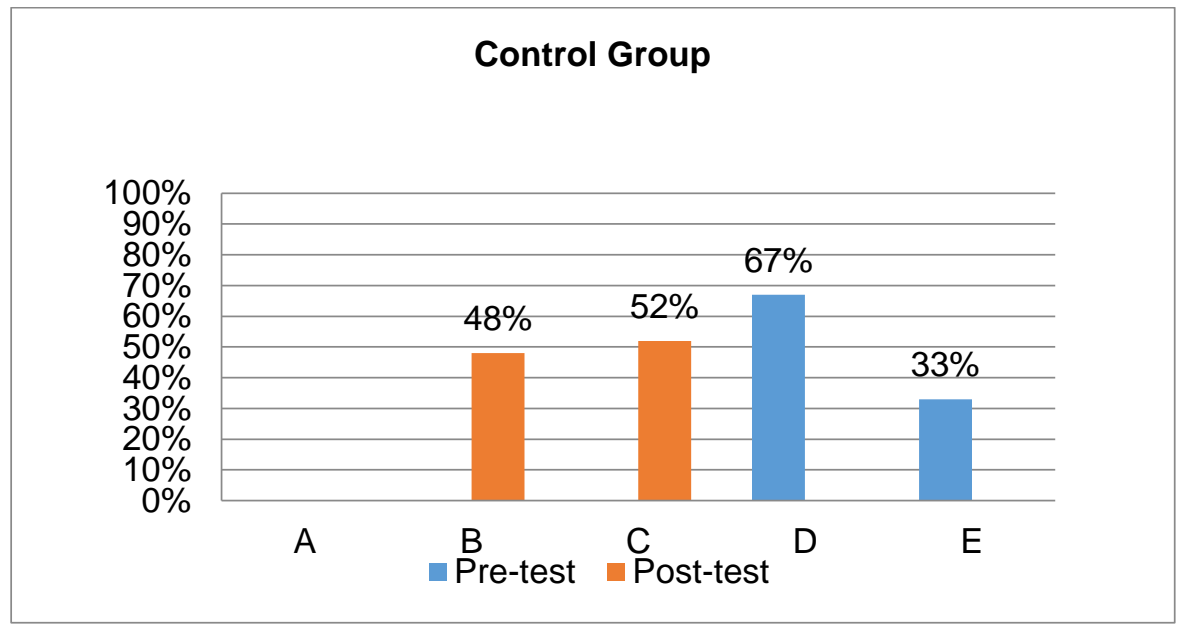

Figure 5. Frequencies of the total scores obtained in the pre-test and post-test by the control and experimental group. 
Source: Direct Research

Created by: Robayo, G. (2017)

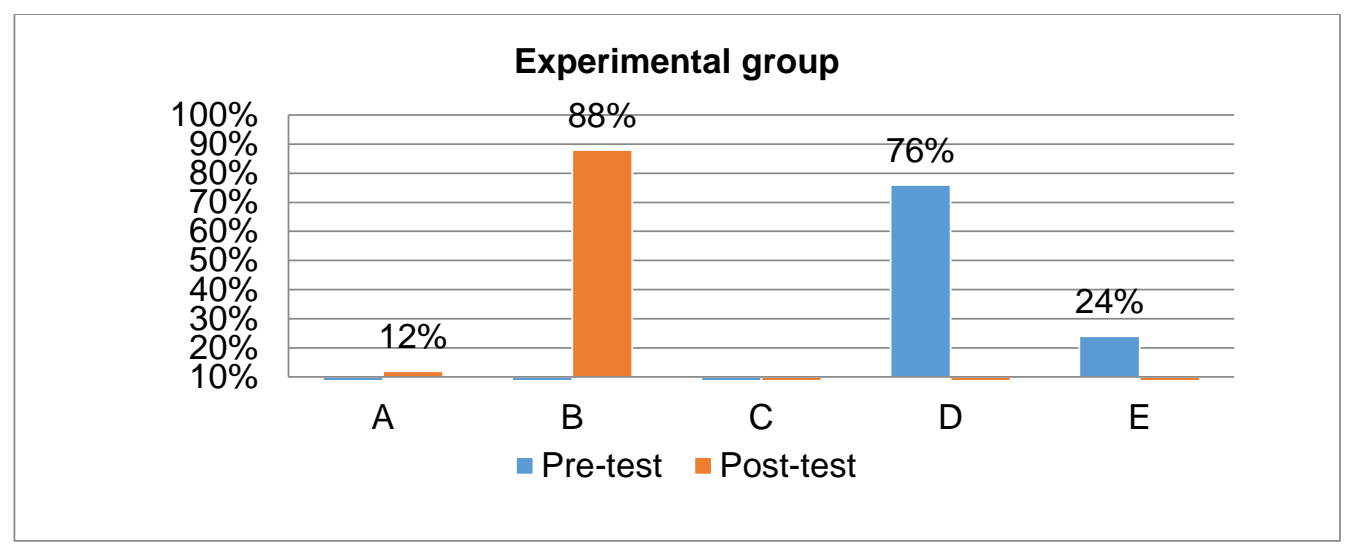

Figure 6. Frequencies of the total scores obtained in the pre-test and post-test by the experimental group.

Source: Direct Research

Created by: Robayo, G. (2017)

In Figure 6 as well as in figure 5and 6, it can be observed the frequency of the total grades obtained by the students from the control and experimental group. In the pre-test, 18 students who represent $67 \%$ of the control group obtained grades from 7-8, this group of students are in the scale "D" needs improvement. 9 students who represent $33 \%$ are in the scale $\mathrm{E}$ unsatisfactory. These percentages varied after the post-test. It can be stated because 14 students who represent $52 \%$ were in the scale "C" satisfactory and 13 students who represent $48 \%$ reached the scale "B" good.

Furthermore, the graphs and figures mentioned in the paragraph above show the following results from the experimental group. In the pre-test, 6 students who represent $24 \%$ obtained grades lower than 6 points, these students were in the scale "E" unsatisfactory, and 19 students that represent $76 \%$ obtained grades from 7-8, they are in the scale "D" needs improvement. However, in the post-test, 22 students who represent $88 \%$ obtained grades from 11-13, they are in the scale "B" Good. In addition, 3 students who represent $12 \%$ got grades from 14-15, they are in the scale "A" excellent.

The comparison of these results; clearly show a difference in the scores in the pre and posttest as well as an increment in the grades from both groups. Nevertheless, the experimental group obtained higher grades than the control group and reached the scale of Excellent. It could suggest that the treatment with project-based learning approach affected positively on the students' scores. 
Apart from that, the hypothesis verification had to be developed. To be made; the means from both the control and experimental group were compared. Thus, a t-test for two small samples was employed for the post-test's results of the control and experimental group. Besides, a t-test for paired samples was employed for the Pre and Post-test's results of the Experimental Group. Moreover, the means of both groups were compared to see whether they are different in the post- test or not. It was necessary to verify if the treatment with project-based learning approach affected positively the students' oral production, because it is really necessary to have a statistic evidence to verify whether the null hypothesis is rejected or not.

\section{T-test}

In order to carry out the T-test for small samples, the post-test from the control and experimental group's scores were used. Besides, in order to develop the t-test for paired samples, the pre-test and post-test's results from the experimental group were used. The results are shown in the graphs as follows.

Chart 5. T-test for two small samples (Control y Experimental Group)

\begin{tabular}{lrr}
\hline \multicolumn{1}{c}{ Parameters } & $\begin{array}{c}\text { Control group } \\
\text { Post-test }\end{array}$ & $\begin{array}{c}\text { Experimental group } \\
\text { Post-test }\end{array}$ \\
\hline Mean & 10,66666667 & 12,52 \\
Variance & 0,615384615 & 0,676666667 \\
Standard deviation & 0,784464541 & 0,822597512 \\
Observations & 27 & 25 \\
Grouped variance & 0,6448 & \\
Degrees of freedom & 50 & \\
Statistics t & $-8,315554937$ & \\
$\mathrm{P}(\mathrm{T}<=\mathrm{t})$ one tailed & $2,71392 \mathrm{E}-11$ & \\
Critic value of $\mathrm{t}$ (one tailed) & 1,675905025 & \\
$\mathrm{P}(\mathrm{T}<=\mathrm{t})$ two tailed & $5,42783 \mathrm{E}-11$ & \\
Critic value of $\mathrm{t}$ (two tailed) & 2,008559112 & \\
\hline
\end{tabular}

Source: Direct Research

Created by: Robayo, G. (2017)

Chart 5 shows the t-test's results for small samples. In order to compare if there is any difference between the means of the control and experimental group, their results were used. In the post-test, the control group's mean was 10.67; whilst the experimental group's mean was 12.52 . The experimental group's mean was clearly higher than the control group's mean. It was observed that the statistics $\mathrm{T}$ was -8.31 , that means that there is a $95 \%$ of reliability for two tailed result which was 5.42. Thus, the null hypothesis was rejected and the alternative hypothesis was accepted due to the difference among the means. In the same way, 
the value of $\mathrm{p}=5.42 \mathrm{E}-07$ is lower than $\alpha=0,05$. For these reasons, the alternative hypothesis is accepted.

Chart 6. T-test for paired samples (Pre-test y Post-test) in the Experimental Group.

\begin{tabular}{|c|c|c|}
\hline Parameter & Pre-test & Post-test \\
\hline Mean & 6,76 & 12,52 \\
\hline Variance & 0,19 & 0,676666667 \\
\hline Standard deviation & 0,435889894 & 0,822597512 \\
\hline Observations & 25 & 25 \\
\hline Pearson correlation coefficient & 0,013944592 & \\
\hline Degrees of freedom & 24 & \\
\hline Statistics t & $-31,11619994$ & \\
\hline $\mathrm{P}(\mathrm{T}<=\mathrm{t})$ one tailed & $3,26916 \mathrm{E}-21$ & \\
\hline Critical value of $t$ (one tailed) & 1,71088208 & \\
\hline $\mathrm{P}(\mathrm{T}<=\mathrm{t})$ two tailed & $6,53832 \mathrm{E}-21$ & \\
\hline Critical value of $t$ (two tailed) & 2,063898562 & \\
\hline
\end{tabular}

Source: Direct Research

Created by: Robayo, G. (2017)

The T-test for paired samples showed an increase in the post-test's scores in relation to the pre-test's grades. In the pre-test the means were (6.76 in the pre-test and 12.52 in the posttest). When contrasted with the statistics T calculated (-31.11) and the critical value two tailed (2.06). It can be seen that there is a difference in the pre and post-test's results. It was also observed that the calculated $\mathrm{t}$ is in the rejected zone to a $95 \%$ of reliability. Thus, the null hypothesis is rejected and the alternative hypothesis is accepted.

Moreover, the Pearson correlation coefficient showed a result of 0,01 which indicates that there is a week relation between the pre and post-test and when contrasted with the $\mathrm{p}$ value for two tailed with a significance level of $5 \%(\mathrm{p}=\mathrm{p}=4,34 \mathrm{E}-16<$ than $\alpha=0,05)$. This suggests that the treatment based on project-based learning approach helped the students in the oral production development. Moreover, once the $\mathrm{p}$ value was contrasted, the results showed that the null hypothesis is totally rejected; therefore, the alternative hypothesis is accepted.

\section{Data interpretation}

The descriptive statistical analysis permitted to organize and present the students' results from the pre and post-test in comparative graphs and figures. It helped to recognize the way in which the treatment with project-based learning approach affected positively to the students' oral production development. It was also observed that the experimental group obtained higher scores than the control group as shown in the graphs and figures above. 
Besides, the T-test (students' distribution) analysis showed differences among the averages (means), proving that there were significant differences between them i.e., the students form the experimental group obtained higher scores in the post-test.

\section{Hypothesis verification}

Higher scores were obtained by the experimental group in comparison to the control's group's scores. Concerning the student's t-test, it helped to verify that the experimental group obtained higher mean than the control group in the post-test. Additionally, when the test for paired samples was carried out, the null hypothesis was rejected; it had a 5\% of significance level. Thus, there is enough evidence to argue that the use of project-based learning approach was an effective tool and affected positively in the scores from the experimental group.

After having developed a rigorous data analysis of the results obtained from the pre and posttest throughout this research. It was verified that the alternative hypothesis was accepted. Therefore, the treatment with project-based learning activities affected positively in the English oral production development, applied to 25 ninth graders at Unidad Educativa Pelileo, located in Pelileo-Tungurahua, in the September 2017 - Jun 2018 school year.

\section{Conclusions}

- Project-Based Learning Activities have not been used for English Oral Production improvement at Unidad Educativa Pelileo. Until the present, teachers have been working without applying these kinds of activities. Teachers are not familiar with Project-Based Learning activities; because there have been not found evidences of these activities either in the secretary's office, in the library, in Deputy Head Master's records nor in the teaching planning. Thus, learners were not given the opportunity to study in a studentcentered environment where they are the principal character in the classroom.

- It has been proved that Project-Based Learning activities developed a positive influence in the students' Oral production development at Unidad Educativa Pelileo. It was identified that these activities could be developed through a wide range of actions such as research papers, multimedia presentations, video documentaries, musical and theatrical performances. Those kinds of activities were suitable in order to foster a student-centered environment. Besides, developing those tasks, the students improved not only the speaking skill, but also their initiative, cooperation, critical thinking and group working skills

- The students' English oral production proficiency level was identified. They obtained low scores in the three parameters according to the rubric which was used for the evaluation in the pre-test (grammar and vocabulary, pronunciation, and interactive communication). Thus, most of the students from both groups obtained grades that were in the scale classified as "needs improvement". A possible solution to overcome this constraint could be the use of Project-Based Learning in class.

- There is a close relationship between Project-Based Learning and Oral Production development. This relation is noticed through the development of a statistics analysis, its results showed differences in the pre and post-test's scores. Therefore, the null hypothesis 
was rejected and the alternative hypothesis was accepted. For that reason, the results suggest that the treatment with Project-Based Learning Approach affected positively in the students' English oral production development.

\section{Reference Bibliography}

Andrew, P. (2012). The Social Construction of Age: Adult Foreign Language Learners. Bristol: Multilingual Matters.

Bailey, K. M. (2003). Practical English Language Teaching: Speaking. (D. Nunan, Ed.) New York: McGraw-Hill.

Barker, J. (2000). The English language Teacher's Handbook: How to teach Large Classes with Few Resources. Amsterdam: John Benjamins Publishing Co.

Biber, D. (2006). University Language: A corpus-based study of spoken and written registers. Amsterdam: John Benjamins Publishing Co.

Brumfit, C. (1986). The Practice of Communicative Teaching. New York: Routledge.

Capraro, M. M., Whitfield, J. G., Etchells, M. J., \& Capraro, R. M. (2016). A Companion to Interdisciplinary Stem Project-Based Learning: For Educators by Educators. Texas: Sense Publishers.

Crystal, D. (2003). English as a Global Language. New York: Cambridge Univesity Press. Halliday, M. (1989). Spoken and Written Language. Oxford: Oxford University Press.

Lane, J., (2016). The ten most spoken languages in the world. Retrieved May 30, 2018 from Babbel Magazine

Leaver, B. L., \& Stryker, S. B. (1989, May). Wiley Online Library., from http://onlinelibrary.wiley.com/doi/10.1111/j.1944-9720.1989.tb02746.x/full Retrieved August 23rd, 2016

Robert, C. (2010). Spoken English: Flourish Your Language. Chandigarh: Abhishek Publications.

Straub, J., Marsh, R. A., \& Whalen, D. J. (2017). Small Spacecraft Development ProjectBased Learning: Implementation and Assessment of an Academic Program. Cham: Springer. 
Tan, J. C., \& Chapman, A. (2016). Project-Based Learning for Academically-Able

Students. Rotterdam: Sense Publishers.

Para citar el artículo indexado.

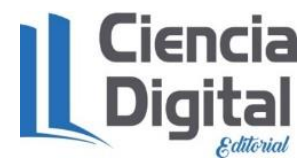

Remache Carrillo, N., Robayo Dávalos, G., \& Yanez Valle, V. (2019). The influence of project-based learning approach in the english oral production. Explorador Digital, 3(3.1), 182-203.

https://doi.org/10.33262/exploradordigital.v3i3.1.880

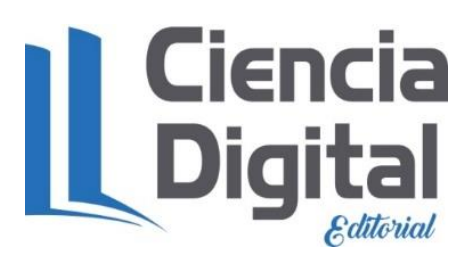

El artículo que se publica es de exclusiva responsabilidad de los autores y no necesariamente reflejan el pensamiento de la Revista Explorador Digital.

El articulo queda en propiedad de la revista y, por tanto, su publicación parcial y/o total en otro medio tiene que ser autorizado por el director o editor de la Revista Explorador

Digital.
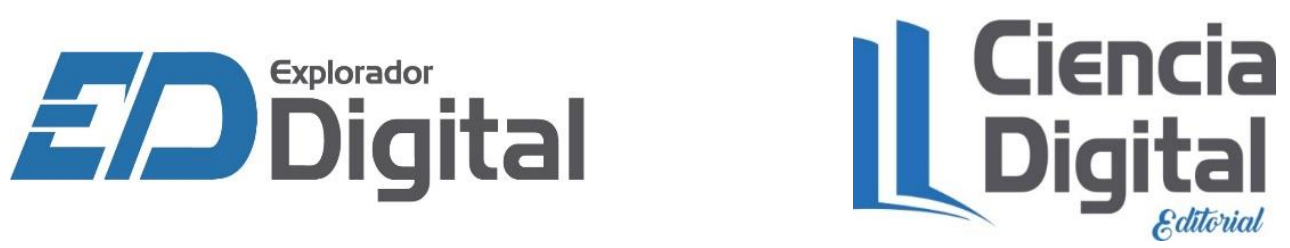